\title{
Comparison of 8 and 24 channels MASW data: Field performance
}

\author{
Eddy Hartantyo $^{1, \mathrm{a}}$, Kirbani Sri Brotopuspito ${ }^{1}$, Sismanto $^{1}$, Waluyo $^{1}$ \\ Geophysics Laboratory, Physics Department, Faculty of Math and Nat Sciences. \\ University of Gadjah Mada \\ Yogyakarta, Indonesia \\ ae-mail: hartantyo@ugm.ac.id
}

\begin{abstract}
The comparison of their frequency-phase velocity (FV) diagrams from both 8 and 24 channels seismic surface wave active data (MASW) have been carried out. This conducted to show the effectiveness of smaller amounts of geophones for MASW acquitision and comparing the processing FV results. Several data were acquired both using 24 full channels geophones as well as using only 8 channels at the same line and locations. Geophone spacing for 24 channles was set to $1 \mathrm{~m}$ and $23 \mathrm{~m}$ total length, otherwise $3 \mathrm{~m}$ and $21 \mathrm{~m}$ total length for 8 channels. These two methods using $3 \mathrm{~m}$ shot offset, by $5 \mathrm{~kg}$ hammer. The data were collected using the same data logger. In theory, the differences of using limited amount of geophones will be influencing the frequency-velocity bandwidth in their FV diagrams. But, this is not true for field case. Several field case shows a similar FV result for these two data, even of course there were small differences between them. For further analysis, subjective manual pickings were have similar results.
\end{abstract}

Keywords : MASW, acquisition, channels, comparison

\section{INTRODUCTION}

Multichannel Analysis of Surface Wave (MASW) is a tools for figuring out the shear velocity beneath the ground surface, based on the surface wave recording and analysis [1]. Unlike the shear-wave survey method that tries to measure directly shear-wave velocities-which is notoriously difficult because of difficulties in maintaining favorable signal-to-noise ratio $(\mathrm{S} / \mathrm{N})$ during both data acquisition and processing stages-MASW is one of the easiest seismic methods that provides highly favorable and competent results [1]. Data acquisition is significantly more tolerant in parameter selection than any other seismic methods because of the highest signal-to-noise ratio $(\mathrm{S} / \mathrm{N})$ easily achieved. This most favorable $\mathrm{S} / \mathrm{N}$ is due to the fact that seismic surface waves are the strongest seismic waves generated that can travel much longer distance than body waves without suffering from noise contamination [2]. The MASW process will creating 1D profile of interpreted shear velocities beneath the survey line-spread. For $2 \mathrm{D}$ section of interpreted shear velocities, first, the Common Mid Point Cross Correlation (CMPCC) method [3] can be used with special acquisition survey, and second, by juxtaposing the $1 \mathrm{D}$ to create $2 \mathrm{D}$ section.

These methods have been extensively used for several activities; subsurface shear velocity mapping for garden/camping ground [4], Bedrock mapping at Olathe Kansas [5], subsurface shallow geology mapping at Alabama
[6], and Foundation analysis of wind turbines in Kansas [7]. Reference [8] also use this method for shallow subsurface weak soil mapping beneath high voltage tower (PLNSUTET), and find a probable weak area conjuring fault near the tower foundation. By combining this method with refraction seismic (creating $\mathrm{P}$ velocity section), elastic properties of subsurface soil is also computed [9]. All of the MASW survey uses 24 geophone channels due to commercial instruments and their included software.

In this paper, we will compare the 24 channels data with more efficient ways (only 8 channels) and see the advantages and disadvantages on both methods. Both data were recorded by commercial instruments (OYO McSeis-24), and processes by FV diagram written in Matlab Code [10].

\section{Methodology}

The location site laid on the Yogyakarta depression, consist of dominantly sand and tuff from volcanic activities (volcano-clastic area) with more than $100 \mathrm{~m}$ thickness [11]. Geographically, the site was located at Sewon, Bantul district, in the south part of Yogyakarta special province, Indonesia. There are 56 site points for MASW measurements. In every site point, the acquisition layout can be seen in Fig. 1. The 24 channels uses $1 \mathrm{~m}$ spacing geophones $(0-23 \mathrm{~m})$, and the 8 channels using $3 \mathrm{~m}$ spacing $(0-21 \mathrm{~m})$. We use two sets of sources, forward and reverse shots at $5 \mathrm{~m}$ offsets. The $5 \mathrm{~kg}$ hammer use as a source. The data were recorded with $1 \mathrm{~ms}$ sampling for 1 second length.

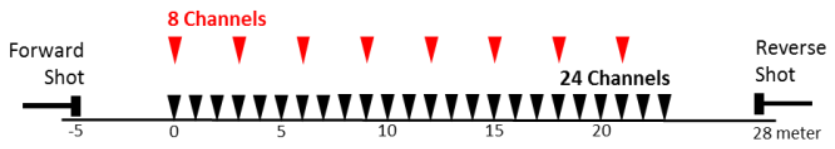

Figure 1. The schematic acquisition of 8 channels (red triangles) and 24 channels (black triangles). Both forward and reverse shots were conducted for consistency check.

Both data then were processed with forward and reverse butterword-lowpass filter $(<50 \mathrm{~Hz})$, and comparing both forward-reverse 24-8 channels in FV (Frequency - Phase Velocity) domain creating with remapping-FK (FrequencyWavenumber) to FV built in Matlab Code. The comparation also provide with special technique [10] by stacking all of similar scheme in FV domain rather than in XT (space-time) domain. The comparison of FV also will be done with commercial software from OYO (seisimager module). 


\section{RESULT AND DISCUSSION}

Fig. 2 was the sample data of chosen site, and shows filtered LBF $50 \mathrm{~Hz}$ of acquired data. Both forward and reverse on 24 channels acquisition shows the Rayleigh waves (strong wave) in both scheme. It is visually seen that the 24 channels (Fig. 2 top) are clearly seen compared with the 8 channels (Fig. 2 bottom) due to lack of channels and drawing capabilities. The signal to noise ratio of all schemes were fair, seen from the wave shape of small riffles before and after the waves signal (both body and surface waves) have been arrived at adjacent geophones.
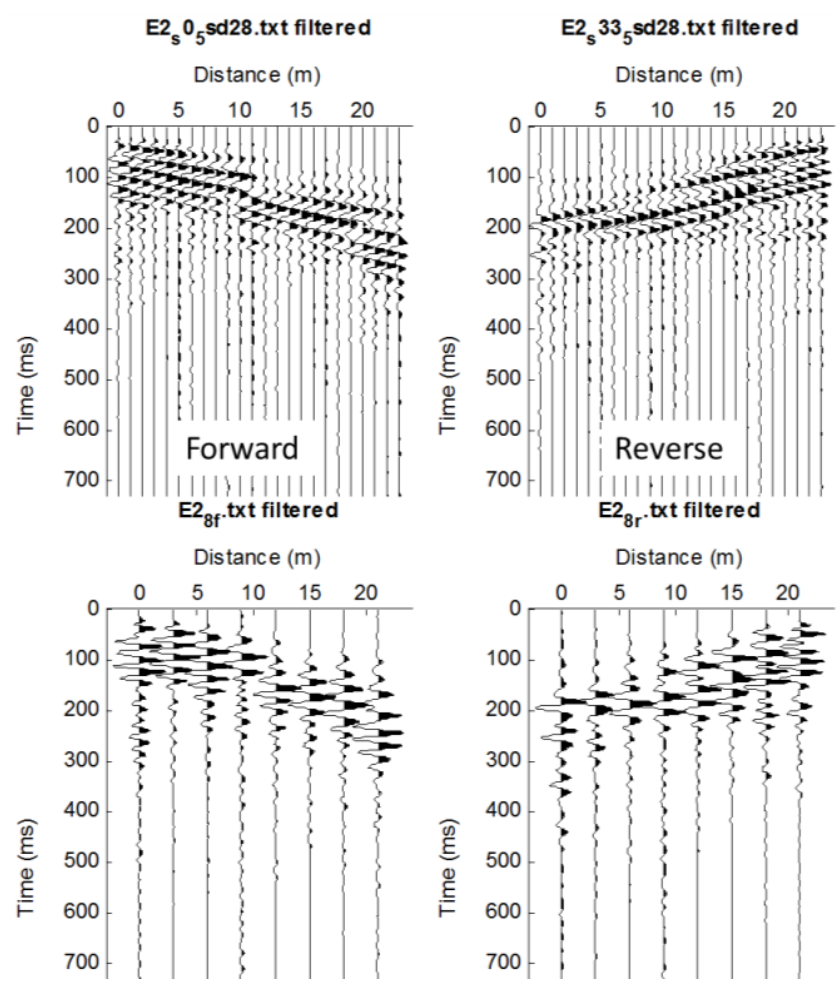

Figure 2. The filtered LBF $50 \mathrm{~Hz}$ of recorded data on 24 channels (top) and 8 channels (bottom) both for forward and reverse shots.

The FV diagram of all four pictures in Figure 2 can be seen in fig 3. The top pictures of Fig. 3 were FV diagram for forward (left) and reverse (right) shot of 24 channels data. In both shots, we can identify the dispersion curve mode 0 and mode 1 of Rayleigh waves. Mode 0 has the smallest phase velocity value (near $170 \mathrm{~m} / \mathrm{s})$ in all used frequencies $(<50 \mathrm{~Hz})$. This mode was usually uses for inversion proses. The forward shot was shown clearly mode 0 of dispersion and easily pick the maximum norm value in each frequencies, otherwise this is not seen in reverse especially in range of $(32-42 \mathrm{~Hz})$. But, for the data below $10 \mathrm{~Hz}$, the reverse shot shows a clearly data compared to forward's one.

The bottom pictures of Fig. 3 is the FV diagrams of 8 channels TX data from Fig. 2 bottom, shows a similar phenomenon both forward and reverse shots using 24 channels. In FV of forward shot, higher error of 8 channels was occur in low frequency below $10 \mathrm{~Hz}$, and the existence of dispersion mode 1 was disappear. There were also small phase velocity differences at frequency $20-25 \mathrm{~Hz}$. Also at the lower channel, the FV diagram relatively vertically spiky which is harder to pick the optimum values of the correct dispersion data. This phenomenon also shows in reverse shot. The spike of diagram at $24 \mathrm{~Hz}$ was relatively high in 8 channels data, and also there are little ripple at $10-20 \mathrm{~Hz}$ frequencies range. Visually there are no differences which disturb interpretation process for data picking in selected frequencies.
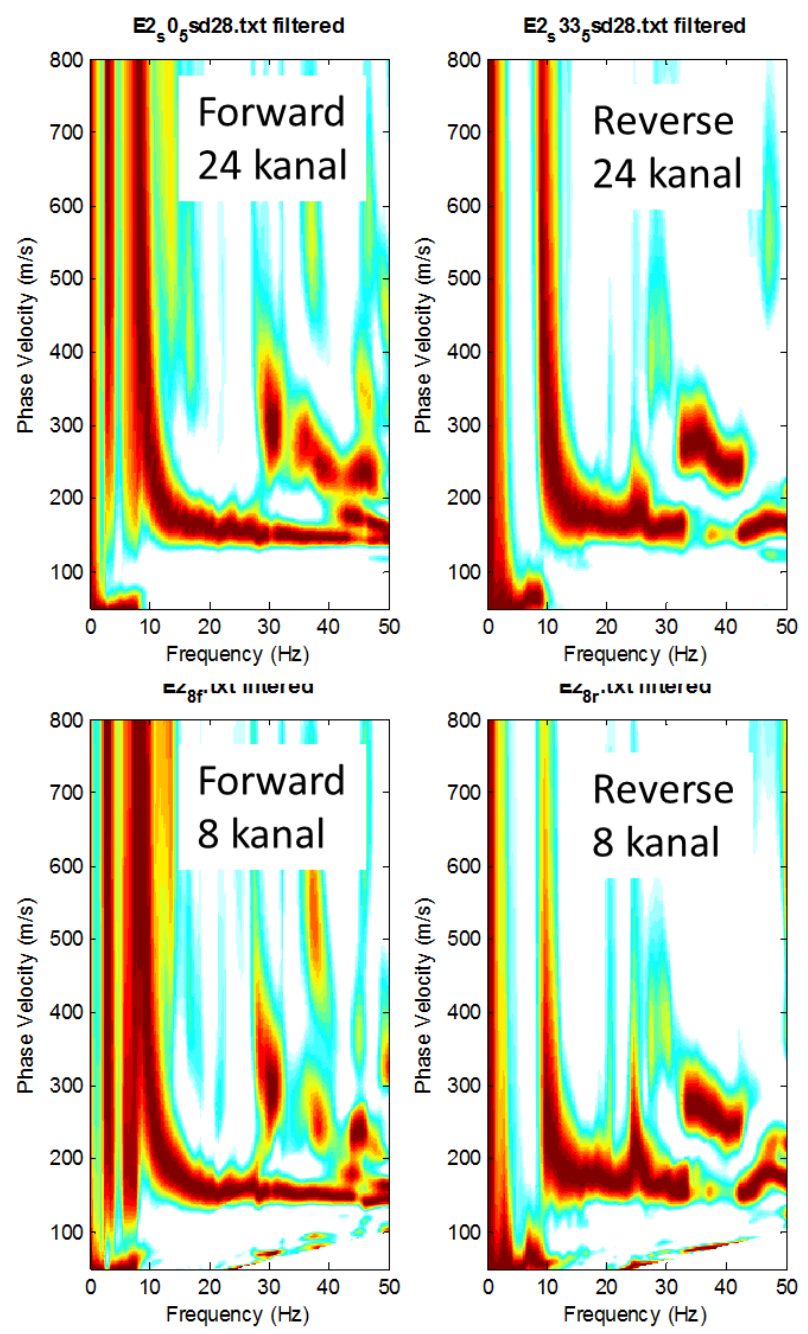

Figure 3. The FV stack of each data at site point A for 24 channels (top) and 8 channels (bottom). The two lines shows theoretically pick data limitations.

The FV data stack of every shots in each 24 and 8 channels can be seen in Fig. 4. The top picture of Fig. 4 is stacked FV diagram for 24 channels including the space range of theoretically area where the FV area are tolerable to pick based on the length of spread (top line) and geophone spacing (bottom line), based on Park et al (1999) criteria. The bottom picture of Fig. 4 is the similar picture but for 8 channels, also with its area limit. Visually, there are no differences between these two pictures, especially if we 
compare from the ease for dispersion data picking. Even, theoretically, at the 8 channels data, there are limitations to pick the data with frequency higher than $25 \mathrm{~Hz}$, the field performance shows the opposite phenomenon. The data still pickable for frequencies higher than $25 \mathrm{~Hz}$, as clear as using 24 channels. From several acquired data, this work shows identical results.
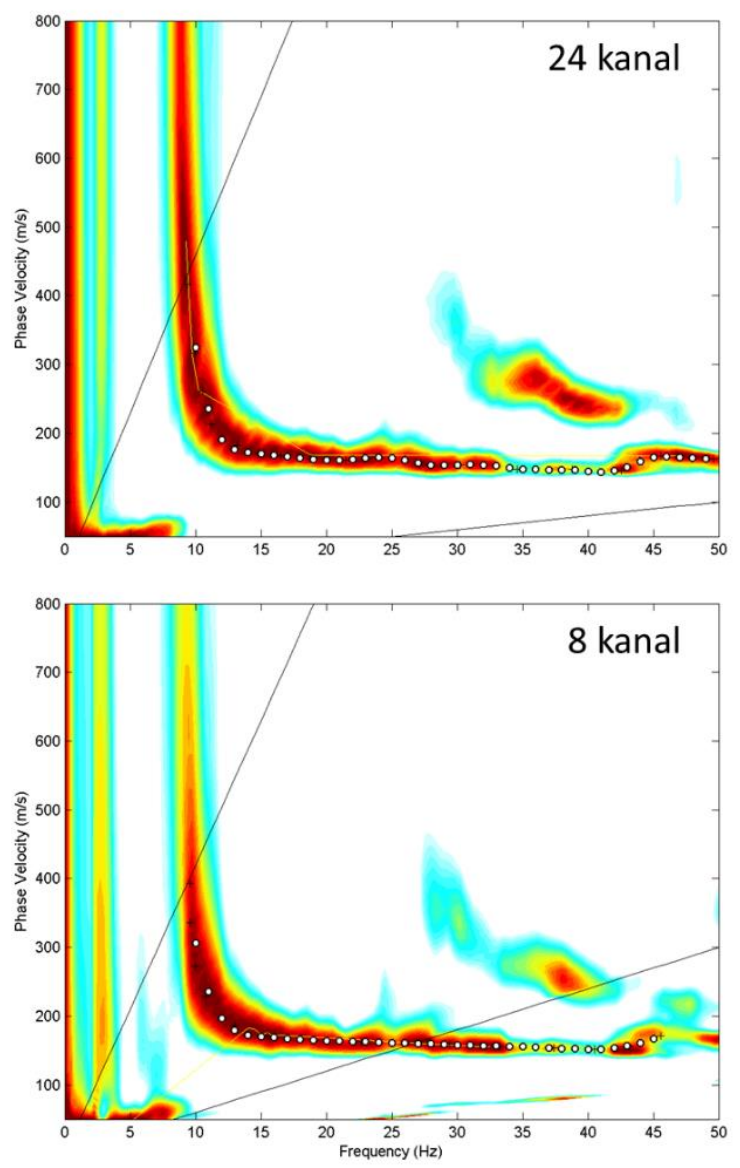

Figure 4. The FV stack of each data at site point A for 24 channels (top) and 8 channels (bottom). The two lines shows theoretically pick data limitations.

\section{CONSLUSIONS}

From several points' site data acquisition, the use of only 8 channels data, in the sense of FV diagram (created with remapped FK diagram) has a reasonable diagram comparing with using 24 channels. The ease of data picking was similar, and based on this process, we need only 8 channels (reduce $66 \%$ ) of geophones used to create similar FV diagram with comparable result. This conclusion is only studied at the area of volcaniclastic sediments. For further analysis and comparation, different areas and surface geology should be investigated for completed this simplified number of geophones.

\section{ACKNOWLEDGMENT}

This work is a part of $\mathrm{PhD}$ dissertation of one of the authors (EH). We acknowledge BPPDN for the Domestic $\mathrm{PhD}$ Scholarship and undergraduate students of Geophysics study program, UGM, for helping during the MASW data acquisition campaign.

\section{REFERENCES}

[1] Park, C.B., Miller, R.D., and Xia, J., 1999, Multi-channel analysis of surface waves, Geophysics, Vol. 64, No. 3 (May-June 1999); pp. 800-808, 7 Figs.

[2] Aki, K., and Richard, P.G., 1980, A Quantitative Seismology: Theory and Methods, vol 1, W.H. Freemann, New York.

[3] Hayashi, K. and Suzuki, H., 2004, CMP cross-correlation analysis of multi-channel surface-wave data; Exploration Geophysics, v 35, 7-13

[4] Park, C.B. and Miller, R.D., 2004, MASW to Map Shear-Wave Velocity of Soil, Kansas Geological Survey Open File Report 200430

[5] Miller, R.D. and Xia, J., 1999, Using MASW to Map Bedrock in Olathe, Kansas, Kansas Geological Survey Open File Report No 999. Final report to Harding Lawson Associates, Lee's summit, Missouri

[6] Xia, J., 2006, Delineating Subsurface Features with the MASW Method at Maxwell AFB in Montgomery, Alabama, Kansas Geological Survey Open File Report No 2006-1. Report to Andrew Weinberg, Bechtel-S Corp., Texas

[7] Park, C.B., and Miller, R.D., 2005, Seismic Characterization of Wind Turbine Sites in Kansas by the MASW Method, Kansas Geological Survey Open File Report 2005-23. Report to Barr Engineering Company, Minneapolis

[8] Hartantyo, E., Afif, R. and Wiwit, S.,2008, Active Multichannel Analysis of Surface Waves (MASW) Survey for SUTET tower base soil compaction imaging, ICMNS Proceeding, 2008, ITB Bandung.

[9] Hartantyo, E., 2009. Joint Analysis of Shallow Subsurface Seismic Properties beneath Extra High Voltage PLN Towers, Proceeding The First International Seminar on Science and Technology, ISSTEC 2009, ISBN:978-979-19201-0-0, Universitas Islam Indonesia, 25 January 2009

[10] Hartantyo, Kirbani S.B., Sismanto, Waluyo., 2014. PhD Dissertation, in progress. Unpublished.

[11] Rahardjo, W., Sukandarrumidi, \& Rosidi, H.M.D., 1995. Geology Map, Yogyakarta Quadrangle, PPPG, Bandung 